\title{
Hemodiyaliz Hastalarının Semptom Yönetiminde Kullanılan İntegratif Yöntemler
}

\author{
Integrative Methods Used for Symptom Management of \\ Hemodialysis Patients
}

\author{
Zeliha BÜYÜKBAYRAM ${ }^{1}, \quad$ Meyreme AKSOY ${ }^{2}$
}

${ }^{I}$ Dr. Öğr. Üyesi- Siirt Üniversitesi Sağlık Bilimleri Fakültesi Hemşirelik Bölümü, İç Hastalıkları Hemşireliği

$A D$, Siirt, Türkiye

${ }^{2}$ Dr. Öğr. Üyesi- Siirt Üniversitesi Sağllk Bilimleri Fakültesi Hemşirelik Bölümü, Hemşirelik Esasları AD, Siirt,

Türkiye

Geliş Tarihi / Received :

18 Ocak/Jan 2021

Kabul Tarihi / Accepted:

30 Ocak/Jan 2021

\section{İletişim yazarı \\ Correspondence author \\ Zeliha BÜYÜKBAYRAM}

E-posta: zeliha_bbayram@hotmail.com

\section{ORCID}

Zeliha BÜYÜKBAYRAM 0000-0001-9152-6662

Meyreme AKSOY

0000-0001-7468-9822

\section{Özet}

Dünyada ve ülkemizde önemli sağlık sorunlarından biri olan kronik böbrek yetmezliği, birçok nedene bağlı olarak gelişebilmektedir. Kronik böbrek yetmezliği, vücudun metabolik ve elektrolit dengesini sürdürme yeteneğinin kaybolması ile sonuçlanan, böbrek fonksiyonlarının ilerleyici ve geriye dönüşsüz olarak bozulmasıdır. Böbrek fonksiyonları ciddi seviyede bozulduğu durumlarda hastanın yaşamı tehlikeye girer. $\mathrm{Bu}$ durumda vücutta biriken atık ve toksik maddelerin vücuttan atılması, vücut sıvı volüm ve homeostazisinin sürdürülmesinde uygulanan tedavi yöntemlerinden biri hemodiyalizdir. Hastalar hemodiyalize bağlı kronik ağrı, kramp, kaşıntı, anksiyete, yorgunluk ve uyku bozukluğu gibi birçok semptom yaşamaktadır. Hemodiyaliz hastalarının yaşadıkları bu semptomların tedavisinde integratif yöntemlerin kullanılması gün geçtikçe yaygınlaşmaktadır. $\mathrm{Bu}$ derlemede hemodiyaliz hastalarının semptom yönetiminde kullanılan bazı integratif yöntemlerle ilgili yapılan çalışma örnekleri hakkında bilgi verilmiştir.

Anahtar Kelimeler: Hemodiyaliz; Hemşirelik; İntegratif yöntemler; Semptom yönetimi

\begin{abstract}
Chronic kidney failure, which is one of the important health problems in the world and our country, can develop due to many reasons. Chronic kidney failure is the progressive and irreversible deterioration of kidney functions that loses the body's ability to maintain metabolic and electrolyte balance. The patient's life is endangered in cases of severe renal impairment. In this case, hemodialysis is one of the treatment methods used to eliminate waste and toxic substances accumulated in the body and to maintain body fluid volume and homeostasis. Patients experience many symptoms such as chronic pain, cramps, itching, anxiety, fatigue and sleep disturbance due to hemodialysis. The use of
\end{abstract}


integrative methods in the treatment of these symptoms experienced by hemodialysis patients is increasing day by day. In this review, information was given about the examples of studies conducted on some integrative methods used in symptom management of hemodialysis patients.

Key Words: Hemodialysis; Nursing; Integrative methods; Symptom management

\section{GíRIŞ}

Kronik Böbrek Yetmezliği (KBY), vücudun metabolik ve elektrolit dengesini sürdürme yeteneğinin kaybolması ile sonuçlanan, böbrek fonksiyonlarının ilerleyici ve geriye dönüşsüz olarak bozulmasıdır (1-3). Dünyada ve ülkemizde önemli sağlık sorunlarından biri olan KBY, diabetes mellitus, hipertansiyon, glomerülonefrit, polikistik böbrek hastalıkları, obstrüktif nefropati gibi birçok nedene bağl1 olarak gelişebilmektedir (3).

Dünya Sağlık Örgütü’nün 2018 raporuna göre, dünya genelinde 2015 y1lında 1.2 milyon kişinin böbrek hastalığı nedeniyle yaşamını kaybettiği, 2005 yılından bu yana ölümlerin \%32 oranında arttığ 1 bildirilmiştir. Aynı raporda, 2010 yılında, dünya genelinde 2.62 milyon kișiye diyaliz tedavisi uygulandığı ve diyaliz tedavisi uygulanan birey sayısının 2030 yılında ikiye katlanacağ 1 bildirilmiştir (2). T.C. Sağlık Bakanlığı ve Türk Nefroloji Derneği (TND) Ortak Raporu 2019 y1lı verilerine göre ise, Türkiye'de renal replasman tedavisi (RRT) gerektiren Son dönem böbrek hastalığının çocuk hastalar dahil edilmediği nokta prevalans1 milyon nüfus başına 1007.6, RRT insidansı ise milyon nüfus başına 150.5 'tir. Türkiye'de RRT'de en çok tercih edilen yöntem hemodiyaliz (HD)'dir. 2019 y1lı sonu itibarıla Türkiye'de 83.783 RRT hastası bulunmakta ve bunların 61.341'i (\%73.21) HD tedavisi almaktadir (3).

Böbrek fonksiyonlarının ciddi seviyede bozulduğu durumlarda hastanın yaşamı tehlikeye girmektedir. Bu durumda vücutta biriken atık ve toksik maddelerin vücuttan atılması, vücut sıv1 volüm dengesinin korunması gerekmektedir (2-5). Böbrek fonksiyon kaybı dönüşümsüz olduğunda, yaşamın sürdürülmesi için farklı tedaviler uygulanmaktadır. $\mathrm{Bu}$ tedavi yöntemlerden biri olan hemodiyaliz tedavisi, hastaların, makineye bağımlı olmasına, iş gücü kaybına, sosyal izolasyon yaşamasına, yaşam biçiminin değişmesine ve yaşam kalitesinin azalmasına neden olmaktadır $(2,6,7)$. Ayrıca tedavi komplikasyonları bireyi fizyolojik, psikolojik, ekonomik, sosyal ve cinsel yönden olumsuz etkilemektedir $(2,6)$.

Hemodiyaliz tedavisi alan hastalarda, hastalık süreci ve hemodiyaliz tedavisi nedeniyle ortaya çıkan semptomları azaltmak için hemşireler tarafından birçok integratif yaklaşım uygulanmaktadır $(1,4,5)$. Bağımsız hemşirelik uygulamalarında önemli yer tutan integratif yöntemler son yıllarda, güvenlikleri, kolay uygulanabilir olmaları ve minimum yan etki göstermeleri nedeniyle hemşirelik uygulamalarında tercih edilmektedir. Hemşirelikte integratif tedavilerin uygulamasının temel felsefesi; bireye bütüncül yaklaşım ile sağlığın optimal seviyeye çıkarılmasını sağlamaktır $(7,8)$. HD hastalarında, aromaterapi, akupunktur, akupresür, masaj, refleksoloji ve müzik terapi gibi integratif yöntemler hemşirelik uygulamalarında sıklıkla tercih edilen yöntemler arasında yer almaktadır (2,9-11).

\section{Aromaterapi}

Günümüzde, birçok hastalığın semptom yönetiminde kullanılan integratif yöntemlerinden biri olan aromaterapi, fiziksel ve ruhsal iyiliği sağlaması için bitkilerden elde edilen esansiyel yağların tedavi amaciyla kullanılmasıdır. Aromaterapi uygulamasında bitkilerden elde edilen uçucu yağlar, çiçek, meyve ve ağaçların kökleri terapötik ajan olarak kullanılmaktadır (5,11-13). Aromaterapi hemşireler tarafindan sıklıkla kullanılan bir integratif yöntemdir $(11,14)$. Önemli komplikasyonlarının olmaması, düşük maliyeti, kullanım kolaylığı ve faydalı etkileri göz önüne alındığında, aromaterapi hemodiyaliz hastalarının semptom yönetiminde tercih edilmektedir $(1,15)$. HD hastalarında aromaterapi uygulamalarının uyku kalitesi, ağrı, kaşıntı, yorgunluk, depresyon ve anksiyete semptomları üzerine etkisini incelemeye yönelik yapılan çalışmalara ilişkin özet bilgiler Tablo 1'de gösterilmektedir. 
Tablo 1. Hemodiyaliz Hastalarında Aromaterapi ile İlgili Yapılan Çalışma Örnekleri

\begin{tabular}{|c|c|c|c|c|}
\hline Yazar ve Yılı & $\begin{array}{c}\text { Kullanılan } \\
\text { İntegratif Yöntem/ } \\
\text { Uygulanma yolu }\end{array}$ & $\begin{array}{l}\text { Araştırma } \\
\text { Tipi }\end{array}$ & Örneklem & Sonuç \\
\hline Lee vd., 2011 (13) & $\begin{array}{l}\text { Lavanta ve tatl } \\
\text { portakal1/ } \\
\text { İnhalasyon }\end{array}$ & $\begin{array}{l}\text { Ön test-son } \\
\text { test yar1 } \\
\text { deneysel }\end{array}$ & $\begin{array}{l}\text { Deney grubu: } 17 \\
\text { Kontrol grubu: } 17\end{array}$ & $\begin{array}{l}\text { Aromaterapinin, HD hastalarında } \\
\text { uyku bozuklukları ve yorgunluğu } \\
\text { azalttığı görülmüştür. }\end{array}$ \\
\hline $\begin{array}{l}\text { Dabirian vd., } \\
2013(14)\end{array}$ & $\begin{array}{l}\text { Lavanta esansiyel } \\
\text { yağ1/ İnhalasyon }\end{array}$ & $\begin{array}{l}\text { Yarı } \\
\text { deneysel } \\
\text { çalışma }\end{array}$ & 53 hasta & $\begin{array}{l}\text { Aromaterapinin, HD hastalarında } \\
\text { uyku kalitesinin olumlu yönde } \\
\text { etkilediği görülmüştür. }\end{array}$ \\
\hline $\begin{array}{l}\text { Bagheri-Nesami } \\
\text { vd., } 2014 \text { (1) }\end{array}$ & $\begin{array}{l}\text { Lavanta esansiyel } \\
\text { yağ1/ İnhalasyon }\end{array}$ & RKÇ & 36 hasta & $\begin{array}{l}\text { Aromaterapinin, fistül giriş bölgesine } \\
\text { ilişkin ağrıyı azaltmada etkili olduğu } \\
\text { saptanmıştır. }\end{array}$ \\
\hline $\begin{array}{l}\text { Cürcani \& Tan, } \\
2014 \text { (15) }\end{array}$ & $\begin{array}{l}\text { Lavanta, çay ağacı, } \\
\text { badem ve jojoba } \\
\text { yağları karışımı/ } \\
\text { Topikal yolla }\end{array}$ & $\begin{array}{l}\text { Ön test-son } \\
\text { test yarı } \\
\text { deneysel }\end{array}$ & $\begin{array}{l}\text { Deney grubu: } 40 \\
\text { Kontrol grubu: } 40\end{array}$ & $\begin{array}{l}\text { Aromaterapinin, HD hastalarının } \\
\text { kaşıntı problemini azalttığını } \\
\text { saptanmıştır. }\end{array}$ \\
\hline $\begin{array}{l}\text { Bagheri Nesami } \\
\text { vd., } 2015(16)\end{array}$ & $\begin{array}{l}\text { Lavanta esansiyel } \\
\text { yağ1/ İnhalasyon }\end{array}$ & RKÇ & $\begin{array}{l}\text { Deney grubu: } 29 \\
\text { Kontrol grubu: } 30\end{array}$ & $\begin{array}{l}\text { Aromaterapinin, HD hastalarında } \\
\text { yorgunluğu azaltmada etkili olmadığ } 1 \\
\text { görülmüştür. }\end{array}$ \\
\hline $\begin{array}{l}\text { Ghods AA vd., } \\
2015 \text { (17) }\end{array}$ & $\begin{array}{l}\text { Lavanta esansiyel } \\
\text { yağ } 1 / \text { Topikal yolla }\end{array}$ & RKÇ & $\begin{array}{l}\text { Deney grubu: } 17 \\
\text { Plasebo grubu: } 17\end{array}$ & $\begin{array}{l}\text { Aromaterapinin, HD iğnelerinin } \\
\text { yerleştirilmesi sırasında hissedilen } \\
\text { ağrıyı azalttığ saptanmıştır. }\end{array}$ \\
\hline $\begin{array}{l}\text { Hashemi vd., } \\
2015(18)\end{array}$ & $\begin{array}{l}\text { Lavanta yağ } 1 / \\
\text { Topikal+masaj } \\
\text { yoluyla }\end{array}$ & RKÇ & $\begin{array}{l}\text { Deney grubu: } 29 \\
\text { Kontrol grubu: } 30\end{array}$ & $\begin{array}{l}\text { Aromaterapinin, HD hastalarında } \\
\text { huzursuz bacak sendromunu } \\
\text { iyileştirmede etkili olduğu } \\
\text { görülmüş̧ür. }\end{array}$ \\
\hline $\begin{array}{l}\text { Aliasgharpour } \\
\text { vd., } 2016(11)\end{array}$ & $\begin{array}{l}\text { Lavanta yağı/ } \\
\text { İnhalasyon }\end{array}$ & $\begin{array}{l}\text { Yarı } \\
\text { deneysel }\end{array}$ & $\begin{array}{l}\text { Deney grubu: } 46 \\
\text { Kontrol grubu: } 46\end{array}$ & $\begin{array}{l}\text { Aromaterapinin, HD hastalarında } \\
\text { arteriyovenöz fistül ağrısını } \\
\text { azaltmada etkili olduğu saptanmıştır. }\end{array}$ \\
\hline $\begin{array}{l}\text { Barati vd., } 2016 \\
\text { (19) }\end{array}$ & $\begin{array}{l}\text { Gül suyu/ } \\
\text { İnhalasyon }\end{array}$ & RKÇ & $\begin{array}{l}\text { Deney grubu: } 23 \\
\text { Kontrol grubu: } 23\end{array}$ & $\begin{array}{l}\text { Aromaterapinin, HD hastalarının } \\
\text { anksiyetesini azalttığı görülmüştür. }\end{array}$ \\
\hline $\begin{array}{l}\text { Bagheri-Nesami } \\
\text { vd., } 2017(20)\end{array}$ & $\begin{array}{l}\text { Lavanta yağı/ } \\
\text { İnhalasyon }\end{array}$ & RKÇ & $\begin{array}{l}\text { Deney grubu: } 35 \\
\text { Kontrol grubu: } 37\end{array}$ & $\begin{array}{l}\text { Aromaterapinin, HD hastalarında } \\
\text { anksiyete ve depresyon düzeylerini } \\
\text { azaltmada etkili olmadığ } \\
\text { görülmüştür. }\end{array}$ \\
\hline $\begin{array}{l}\text { Muz \& Taşc1, } \\
2017(21)\end{array}$ & $\begin{array}{l}\text { Portakal ve lavanta } \\
\text { yağı / İnhalasyon }\end{array}$ & RKÇ & $\begin{array}{l}\text { Deney grubu: } 27 \\
\text { Kontrol grubu: } 35\end{array}$ & $\begin{array}{l}\text { HD hastalarında uygulanan } \\
\text { aromaterapinin uyku kalitesini } \\
\text { artırdığ } 1 \text {, yorgunluk seviyesini ve } \\
\text { şiddetini azalttığ } 1 \text { tespit edilmiştir. }\end{array}$ \\
\hline $\begin{array}{l}\text { Bouya vd., } 2018 \\
\text { (5) }\end{array}$ & Aromaterapi & $\begin{array}{l}\text { Sistematik } \\
\text { çalışma }\end{array}$ & 22 çalışma & $\begin{array}{l}\text { Aromaterapinin, HD hastalarında } \\
\text { anksiyete, yorgunluk, kaşıntı, uyku } \\
\text { kalitesi, depresyon, stres ve baş ağrısı } \\
\text { gibi hemodiyalizin bazı } \\
\text { komplikasyonlarını azalttığı ve yaşam } \\
\text { kalitesini artırdığı saptanmıştır. }\end{array}$ \\
\hline $\begin{array}{l}\text { Hassanzadeh vd., } \\
2018 \text { (22) }\end{array}$ & $\begin{array}{l}\text { Lavanta yağı/ } \\
\text { İnhalasyon ve } \\
\text { gevşeme tekniği }\end{array}$ & RKÇ & $\begin{array}{l}\text { Kontrol grubu: } 35 \\
\text { inhalasyon } \\
\text { aromaterapi : } 35 \\
\text { gevşeme tekniği } \\
\text { grubu:35 }\end{array}$ & $\begin{array}{l}\text { Aromaterapinin gevşeme tekniğine } \\
\text { göre daha çok yorgunluk düzeyini } \\
\text { azalttığ1 görülmüş̧ür. }\end{array}$ \\
\hline $\begin{array}{l}\text { Şentürk \& } \\
\text { Tekinsoy Kartın, } \\
2018(8)\end{array}$ & $\begin{array}{l}\text { Lavanta yağı/ } \\
\text { İnhalasyon }\end{array}$ & RKÇ & $\begin{array}{l}\text { Deney grubu: } 17 \\
\text { Kontrol grubu:17 }\end{array}$ & $\begin{array}{l}\text { Aromaterapinin, HD hastalarında } \\
\text { uyku sorunları ve anksiyete düzeyleri } \\
\text { üzerinde olumlu etkisi olduğu } \\
\text { saptanmıştır. }\end{array}$ \\
\hline
\end{tabular}


Tablo 1. Devam

\begin{tabular}{|c|c|c|c|c|}
\hline Yazar ve Yılı & $\begin{array}{c}\text { Kullanılan } \\
\text { İntegratif Yöntem/ } \\
\text { Uygulanma yolu }\end{array}$ & $\underset{\text { Tipi }}{\text { Araștırma }}$ & Örneklem & Sonuç \\
\hline $\begin{array}{l}\text { Ahmady vd., } \\
2019 \text { (23) }\end{array}$ & $\begin{array}{l}\text { Lavanta-portakal } \\
\text { yağ1/ İnhalasyon }\end{array}$ & RKÇ & $\begin{array}{l}\text { Deney grubu: } 30 \\
\text { Deney grubu: } 30 \\
\text { Kontrol grubu: } 30\end{array}$ & $\begin{array}{l}\text { Aromaterapi uygulamasının, HD } \\
\text { hastalarında yorgunluğu azalttığ } 1 \\
\text { saptanmıştır. }\end{array}$ \\
\hline $\begin{array}{l}\text { Karadag \& } \\
\text { Samancioglu } \\
\text { Baglama, } \\
2019(24)\end{array}$ & Lavanta-aromaterapi & RKÇ & $\begin{array}{l}\text { Deney grubu: } 30 \\
\text { Kontrol grubu: } 30\end{array}$ & $\begin{array}{l}\text { Aromaterapinin, HD hastalarında } \\
\text { anksiyete ve yorgunluk düzeylerini } \\
\text { azaltmada etkili olduğu görülmüştür. }\end{array}$ \\
\hline $\begin{array}{l}\text { Taşan vd., } \\
2019(25)\end{array}$ & $\begin{array}{l}\text { Lavanta yağı / } \\
\text { İnhalasyon }\end{array}$ & RKÇ & $\begin{array}{l}\text { Deney grubu: } 30 \\
\text { Kontrol grubu: } 30\end{array}$ & $\begin{array}{l}\text { Aromaterapinin, HD hastalarında damar } \\
\text { yolu sırasında yaşadıkları ağrı düzeyini } \\
\text { azalttığı ve olumsuz bir etkiye neden } \\
\text { olmadığı görülmüştür. }\end{array}$ \\
\hline $\begin{array}{l}\text { Reyes vd., } \\
2020(12)\end{array}$ & $\begin{array}{l}\text { Portakal-aromaterapi/ } \\
\text { İnhalasyon }\end{array}$ & $\begin{array}{l}\text { Yarı } \\
\text { deneysel } \\
\text { çalışma }\end{array}$ & $\begin{array}{l}\text { Deney grubu: } 25 \\
\text { Kontrol grubu: } 25\end{array}$ & $\begin{array}{l}\text { Aromaterapi uygulamasının HD } \\
\text { hastalarında hem ağrı hem de anksiyete } \\
\text { düzeylerini düşürdüğü saptanmıştır. }\end{array}$ \\
\hline $\begin{array}{l}\text { Varaei vd., } \\
2020(28)\end{array}$ & $\begin{array}{l}\text { Lavanta yağı / } \\
\text { İnhalasyon }\end{array}$ & RKÇ & $\begin{array}{l}\text { Kontrol grubu: } 32 \\
\text { inhalasyon } \\
\text { Aromaterapi : } 32 \\
\text { Aromaterapi masaj } \\
\text { grubu:32 }\end{array}$ & $\begin{array}{l}\text { Aromaterapi masajının yorgunluk üzerin- } \\
\text { deki etkileri inhalasyon aromaterapisin- } \\
\text { den daha güçlü olmasına rağmen, uçucu } \\
\text { yağlarla yapılan müdahaleler HD } \\
\text { hastalarında yorgunluğu azaltmada etkili } \\
\text { olduğu görülmüştür. }\end{array}$ \\
\hline
\end{tabular}

RKÇ: Randomize kontrollü çalışma

\section{Akupunktur ve Akupresür}

Geleneksel Çin tıbbında yaklaşık 3000 yıldır kullanılan akupunktur, vücuttaki belli noktalara iğne batırılarak gerçekleştirilen bir tedavi yöntemidir. Bu yöntem birçok kronik hastalığın semptomlarını tedavi etmek amaciyla kullanılmaktadır (29,30). Akupresür, akupunkturla aynı meridyen ve aynı noktalar üzerine yapılması nedeniyle temelinde akupunktura dayanmaktadır. Akupresürün akupunkturdan uygulama fark1 ise, iğne yerine el, parmak ya da ayaklar yardımıyla vücudun belirlenen bölgelerine basinç uygulanıyor olmasıdır. Bu nedenle acısız, ağrısız, güvenli, etkili, yan etkisi olmayan, öğrenilmesi ve uygulaması kolay olan bir tedavi yöntemidir (30-32). Akupunktur ve akupresürün HD hastalarında, depresyon, bulantı-kusma, kaşıntı, kas krampları ve yorgunluğu azalttığ iyileştirdiği, yaşam kalitesini olumlu etkilediği görülmüştür $(6,33,34,36)$. HD hastalarında akupunktur ve akupresür ile ilgili yapılan çalışma örnekleri Tablo 2'de gösterilmektedir.

\section{Masaj}

Dünyadaki en eski tedavi yöntemlerinden biri olan masaj, tedavi edici etkisi, palyatif bakımın sürdürülmesi ve dinlenme amaciyla uygulanmak- tadır. Masaj; cildi, kasları, tendonları ve bağları ovuşturmak, bastırmak ve manipüle etmek için kullanılan genel bir terimdir ve temeli dokunmaya dayanmaktadır. Vücudun yumuşak dokularının elle veya mekanik olarak uyarılması olarak da tanımlanmaktadır $(11,43,45)$. Masaj, birçok hastalığın semptom yönetiminde en sık kullanılan integratif yöntemler arasında yer almaktadır $(18,43,44)$. Masaj, omurilik seviyesinde ve subkortikal çekirdeklerde artmış nöral aktiviteye yol açabilecek ve ağrı algısını ve ruh halini etkileyebilecek yerel biyokimyasal değişiklikler oluşturmaktadır. Masaj terapisi ile artan serotonin ve endorfin bireyin ağrı, anksiyete ve depresyon düzeyini azaltabilmektedir (18,45). Masaj, kan dolaşımını arttırarak bölgede biriken metabolitlerin uzaklaştırılmasında, kasların gevşemesinin sağlanmasında, damarsal, sinirsel, hormonal yapıların uyarılmasında ve hücresel faaliyetlerin hızlandırılmasında etkilidir $(11,18,45)$. HD hastalarına yönelik yapılan çalışmalarda; masajın ağr1, yorgunluk, kaşıntı, huzursuz bacak sendromu (HBS) ve yaşam kalitesi üzerinde faydalı etkileri olduğu saptanmıştır $(11,18,46,48)$. Hemodiyaliz hastalarında masaj ile ilgili yapılan çalışmalara ilişkin sonuçlar Tablo 3'te gösterilmektedir. 
Tablo 2. Hemodiyaliz Hastalarında Akupunktur ve Akupresür Yöntemi ile İlgili Yapılan Çalışma Örnekleri

\begin{tabular}{|c|c|c|c|c|}
\hline Yazar ve yılı & $\begin{array}{l}\text { Kullanılan integratif } \\
\text { yöntem ve noktalar }\end{array}$ & $\begin{array}{l}\text { Araştırma } \\
\text { tipi }\end{array}$ & Örneklem & Sonuç \\
\hline $\begin{array}{l}\text { Shariati vd., } \\
2012(34)\end{array}$ & $\begin{array}{l}\text { Akupresür/(He7), (LI4) } \\
\text { (SP6) noktaları }\end{array}$ & RKÇ & $\begin{array}{l}\text { Deney grubu: } 22 \\
\text { Kontrol grubu: } 22\end{array}$ & $\begin{array}{l}\text { Akupresürun, HD hastalarında uyku } \\
\text { kalitesini iyileştirmede etkili olduğu } \\
\text { saptanmıştır. }\end{array}$ \\
\hline $\begin{array}{l}\text { Eğlence vd., } \\
2013(33) \\
\end{array}$ & $\begin{array}{l}\text { Akupresür/ ST36), (GB34), } \\
\text { (SP6), (K1) noktalar1 }\end{array}$ & Deneysel & $\begin{array}{l}\text { Deney grubu: } 52 \\
\text { Kontrol grubu: } 66\end{array}$ & $\begin{array}{l}\text { Akupresürün HD hastalarında yorgunluğu } \\
\text { azaltmada etkili olduğu bulunmuştur. }\end{array}$ \\
\hline $\begin{array}{l}\text { K1lıç Akça vd., } \\
2013 \text { (35) }\end{array}$ & $\begin{array}{l}\text { Akupunktur/(SP6), (SP10), } \\
\text { (LI11) (ST36) noktalar1 }\end{array}$ & RKÇ & $\begin{array}{l}\text { Deney grubu: } 38 \\
\text { Kontrol grubu: } 40\end{array}$ & $\begin{array}{l}\text { Akupresürün HD hastalarında kaşıntıyı } \\
\text { azaltmada etkili olduğu bulunmuştur. }\end{array}$ \\
\hline $\begin{array}{l}\text { Sabouhi vd., } \\
2013(6)\end{array}$ & $\begin{array}{l}\text { Akupresür /(K1), (GB } \\
\text { 34), (ST 36), (SP6), (BL } \\
\text { 23) (HT7) noktaları }\end{array}$ & RKÇ & $\begin{array}{l}\text { Deney grubu: } 32 \\
\text { Plasebo grubu: } 32 \\
\text { Kontrol grubu: } 32\end{array}$ & $\begin{array}{l}\text { Akupresürün HD hastalarında yorgunluğu } \\
\text { azalttığ1 göstermiştir. }\end{array}$ \\
\hline $\begin{array}{l}\text { Wu vd., } 2014 \\
(31)\end{array}$ & Kulak akupunkturu & $\begin{array}{l}\text { Pilot } \\
\text { çalışma }\end{array}$ & 22 Hasta & $\begin{array}{l}\text { Akupunkturun, HD hastalarında uyku } \\
\text { kalitesini arttırdığı görülmüştür. }\end{array}$ \\
\hline $\begin{array}{l}\text { Hmwe vd., } \\
2015 \text { (36) }\end{array}$ & $\begin{array}{l}\text { Akupresür/ (GV 29), (HT } \\
\text { 7), (KI 3) noktakarı }\end{array}$ & RKÇ & $\begin{array}{l}\text { Deney grubu: } 54 \\
\text { Kontrol grubu: } 54\end{array}$ & $\begin{array}{l}\text { Akupresürün HD hastalarında depresyon, } \\
\text { anksiyete, stres ve genel psikolojik rahat- } \\
\text { sızlığı önemli ölçüde azalttığı saptanmıştır }\end{array}$ \\
\hline $\begin{array}{l}\text { Zou vd., } 2015 \\
(30)\end{array}$ & $\begin{array}{l}\text { Akupunktur /(TF4), } \\
\text { (AH6a), (AT4),(CO15), } \\
\text { (CO18) noktaları }\end{array}$ & RKÇ & $\begin{array}{l}\text { Deney grubu: } 32 \\
\text { Plasebo grubu: } 31\end{array}$ & $\begin{array}{l}\text { Akupunkturun HD hastalarında uykusuz- } \\
\text { luğu azaltmada etkili olduğu bulunmuştur. }\end{array}$ \\
\hline $\begin{array}{l}\text { Arab vd., } 2016 \\
(37)\end{array}$ & $\begin{array}{l}\text { Akupresür /(HT7) } \\
\text { noktası }\end{array}$ & RKÇ & $\begin{array}{l}\text { Deney grubu: } 32 \\
\text { Plasebo grubu: } 30 \\
\text { Kontrol grubu: } 31\end{array}$ & $\begin{array}{l}\text { Akupresürün HD hastalarında uyku } \\
\text { kalitesi üzerinde olumlu bir etkisinin } \\
\text { olduğu bulunmuştur. }\end{array}$ \\
\hline $\begin{array}{l}\text { Hadadian vd., } \\
2016(29)\end{array}$ & $\begin{array}{l}\text { Akupunktur /(ST36), } \\
\text { (SP6), (LI4) noktaları }\end{array}$ & RKÇ & $\begin{array}{l}\text { Deney grubu: } 28 \\
\text { Kontrol grubu: } 28\end{array}$ & $\begin{array}{l}\text { Akupresürün, HD hastalarında yorgunluğu } \\
\text { azaltmada etkili bir yöntem olduğunu } \\
\text { belirlemişlerdir. }\end{array}$ \\
\hline $\begin{array}{l}\text { Mohmadi vd., } \\
2016(9)\end{array}$ & $\begin{array}{l}\text { Akupresür /(B57), } \\
\text { (GV26), (LV3), (CV4), } \\
\text { (CV6), (K1), (LU7), } \\
\text { (LU9) noktalar1 }\end{array}$ & $\begin{array}{l}\text { Tek kör bir } \\
\text { klinik } \\
\text { çalışma }\end{array}$ & $\begin{array}{l}\text { Deney grubu: } 32 \\
\text { Kontrol grubu: } 32\end{array}$ & $\begin{array}{l}\text { Akupresür, HD hastalarında kas } \\
\text { kramplarının azaltmada etkili olduğu } \\
\text { saptanmıştır. }\end{array}$ \\
\hline $\begin{array}{l}\text { Shen vd., } 2017 \\
(38)\end{array}$ & $\begin{array}{l}\text { Akupresür /(HT7), K11 } \\
\text { Zhongquan (EXEU3), } \\
\text { sham (S) noktaları }\end{array}$ & RKÇ & $\begin{array}{l}\text { Akupunktur grubu: } 21 \\
\text { Plasebo grubu: } 21\end{array}$ & $\begin{array}{l}\text { Akupresürün, HD hastalarında uyku ve } \\
\text { yaşam kalitesini üzerinde olumlu etkinin } \\
\text { olmadığı saptanmıştır. }\end{array}$ \\
\hline $\begin{array}{l}\text { Yu vd., } 2017 \\
(32)\end{array}$ & $\begin{array}{l}\text { Akupunktur /(LI4), } \\
\text { (ST36) (KI3) noktaları }\end{array}$ & RKÇ & $\begin{array}{l}\text { Akupunktur grubu: } \\
30 \\
\text { Plasebo grubu: } 29\end{array}$ & $\begin{array}{l}\text { Akupunkturun HD hastalarında kreatin } \\
\text { düzeylerini düşürdüğü saptanmıştır. }\end{array}$ \\
\hline $\begin{array}{l}\text { Nahidi vd., } \\
2018 \text { (39) }\end{array}$ & $\begin{array}{l}\text { akupunktur /(Sp6), } \\
(\text { Sp10), (Liv3), (Liv4), } \\
\text { (Liv11) noktalar1 }\end{array}$ & RKÇ & $\begin{array}{l}\text { Deney grubu: } 15 \\
\text { Kontrol grubu: } 21\end{array}$ & $\begin{array}{l}\text { Akupunkturun, HD hastalarında kaşıntıyı } \\
\text { azalttığı saptanmıştır. }\end{array}$ \\
\hline $\begin{array}{l}\text { Abbasi vd., } \\
2019(40)\end{array}$ & $\begin{array}{l}\text { Akupresür/ (Liv4), } \\
\text { (Liv3), (ST36), (SP15) } \\
\text { noktalar1 }\end{array}$ & $\begin{array}{l}\text { Randomize, } \\
\text { çift kör, } \\
\text { plasebo } \\
\text { kontrollü }\end{array}$ & $\begin{array}{l}\text { Deney grubu: } 35 \\
\text { Kontrol grubu: } 35\end{array}$ & $\begin{array}{l}\text { Akupresürün, HD’ye giren hastalarda } \\
\text { kabızlık için etkili bir yöntem olduğu } \\
\text { görülmüştür. }\end{array}$ \\
\hline $\begin{array}{l}\text { Karjalian vd., } \\
2020(41)\end{array}$ & $\begin{array}{l}\text { Akupresür (SP6), (SP10), } \\
\text { (ST36), (LI11) noktalar1 }\end{array}$ & RKÇ & $\begin{array}{l}\text { Deney grubu: } 30 \\
\text { Plasebo grubu: } 30 \\
\text { Kontrol grubu: } 30\end{array}$ & $\begin{array}{l}\text { Akupresürün, hemodiyaliz hastalarında } \\
\text { kaşıntıyı azalttığı saptanmıştır. }\end{array}$ \\
\hline $\begin{array}{l}\text { Wang vd., } \\
2020(42)\end{array}$ & Akupresür & $\begin{array}{l}\text { Meta analiz } \\
\text { çalışma }\end{array}$ & 7 Çalışma & $\begin{array}{l}\text { Akupresürün HD hastalarında uyku } \\
\text { kalitesinin iyileştirmede etkili olduğu } \\
\text { saptanmıştır. }\end{array}$ \\
\hline
\end{tabular}

RKÇ: Randomize kontrollü çalışma

(Kalp-Heart/HE7-HT), (Kalın bağırsak-Large Intestine/LI4-CO), (Dalak-Spleen/SP6), (Mide-Stomach/ST36), (Safra kesesiGall bladder/GB34), (Böbrek-Kidney/K1), (Karaciğer-Liver/Liv11-LV3-LI), (Mesane Meridyeni-Bladder Meridian/BL 23), (Kaşın medial uçları-Yin Tang/GV 29), (Kulak kısmında-Shen men/HT 7), (Medial malleolün ucu ile Aşil tendonunun orta nokta-Taixi/KI 3), (Kulak kısmında-Shen Men/TF4), (sempatik/AH6a), (subcortex/AT4), (Endokrin- Endocrine/CO18), (Alıcı Damar Meridyeni-Conception Vessel Meridian/CV4), (Akciğer meridyeni-Lung/LU7) (6,9,33,34,35,39). 
Tablo 3. Hemodiyaliz Hastalarında Masaj Yöntemi ile İlgili Yapılan Çalışma Örnekleri

\begin{tabular}{|c|c|c|c|c|}
\hline Yazar ve yılı & $\begin{array}{l}\text { Kullanılan } \\
\text { yöntem ve } \\
\text { uygulama } \\
\text { bölgesi }\end{array}$ & $\begin{array}{l}\text { Araştırma } \\
\text { tipi }\end{array}$ & Örneklem & Sonuç \\
\hline $\begin{array}{l}\text { Hashemi vd., } \\
2015 \text { (18) }\end{array}$ & $\begin{array}{l}\text { Her iki bacağa } \\
\text { Lavanta yağı ile } \\
\text { masaj }\end{array}$ & RKÇ & $\begin{array}{l}\text { Deney grubu: } 35 \\
\text { Kontrol grubu: } 35\end{array}$ & $\begin{array}{l}\text { Masajın, HBS'nin şiddetini } \\
\text { azalttığı görülmüştür. }\end{array}$ \\
\hline $\begin{array}{l}\text { Aghajani \& } \\
\text { Kheirkhah, } 2016 \\
(45)\end{array}$ & $\begin{array}{l}\text { Gliserin yağı ile } \\
\text { yapılan masaj }\end{array}$ & RKÇ & $\begin{array}{l}\text { Deney grubu: } 17 \\
\text { Kontrol grubu: } 17\end{array}$ & $\begin{array}{l}\text { Masajın, HBS şiddetini } \\
\text { azalttığı belirlenmiştir. }\end{array}$ \\
\hline $\begin{array}{l}\text { Shahdadi vd., } \\
2016(44)\end{array}$ & Surt masaj1 & - & $\begin{array}{l}\text { Deney grubu: } 26 \\
\text { Kontrol grubu: } 26\end{array}$ & $\begin{array}{l}\text { Masaj uygulamasının HD } \\
\text { hastalarında yorgunluk } \\
\text { düzeyini düşürdüğü } \\
\text { bildirilmiştir. }\end{array}$ \\
\hline $\begin{array}{l}\text { Ghavami vd., } \\
2019(46)\end{array}$ & $\begin{array}{l}\text { Vücudun } 5 \\
\text { çakra bölgesine } \\
\text { sicak taşla } \\
\text { masaj }\end{array}$ & RKÇ & $\begin{array}{l}\text { Deney grubu: } 30 \\
\text { Kontrol grubu: } 30\end{array}$ & $\begin{array}{l}\text { HD hastalarında sıcak taşla } \\
\text { masaj uygulamasının uyku } \\
\text { kalitesini arttırdığı } \\
\text { saptanmıştır. }\end{array}$ \\
\hline $\begin{array}{l}\text { Khorsand vd., } \\
2019 \text { (47) }\end{array}$ & $\begin{array}{l}\text { Menekşe yağ } 1 \\
\text { ile el masajı }\end{array}$ & RKÇ & $\begin{array}{l}\text { Masaj grubu:27 } \\
\text { Menekşe yağı ile } \\
\text { masaj grubu: } 25\end{array}$ & $\begin{array}{l}\text { Menekşe yağı ile masajın tek } \\
\text { başına masajdan daha etkili } \\
\text { olduğu ve üremik kaşıntılı } \\
\text { hastalarda tamamlayıcı bir } \\
\text { tedavi olarak önerildiği } \\
\text { belirtilmiştir. }\end{array}$ \\
\hline $\begin{array}{l}\text { Efe Arslan \& } \\
\text { Kilıç Akça, } 2020 \\
(26)\end{array}$ & $\begin{array}{l}\text { Lavanta yağı ile } \\
\text { el masajı }\end{array}$ & RKÇ & $\begin{array}{l}\text { Deney grubu: } 22 \\
\text { Kontrol grubu: } 22\end{array}$ & $\begin{array}{l}\text { HD hastalarında aromaterapi } \\
\text { el masajının, stresi azalttığı, } \\
\text { uyku kalitesini artırdığı ve } \\
\text { uyku ilacı kullanımını } \\
\text { azalttığı görülmüştür. }\end{array}$ \\
\hline $\begin{array}{l}\text { Habibzadeh vd., } \\
2020 \text { (48) }\end{array}$ & Ayak masajı & $\mathrm{RKÇ}$ & 120 hasta & $\begin{array}{l}\text { HD hastalarında ayak } \\
\text { masajının, yorgunluk } \\
\text { şiddetini azalttığı ve yaşam } \\
\text { kalitesini iyileştirmede etkili } \\
\text { olduğu görülmüştür. }\end{array}$ \\
\hline $\begin{array}{l}\text { Mohammadpourh } \\
\text { odki vd., } 2020 \\
(27)\end{array}$ & $\begin{array}{l}\text { Her iki bacak ve } \\
\text { ayağa Citrus } \\
\text { Aurantium } \\
\text { esansiyel yağı } \\
\text { ile masaj }\end{array}$ & $\mathrm{RKÇ}$ & $\begin{array}{l}\text { Lavanta yağı: } 35 \\
\text { Narenciye Aurantium } \\
\text { Esansiyel grubu:35 } \\
\text { Kontrol grubu: } 35\end{array}$ & $\begin{array}{l}\text { Her iki aromaterapi masajının } \\
\text { HD hastalarının yaşam } \\
\text { kalitesine olumlu etkileri } \\
\text { olduğu bulunmuştur. }\end{array}$ \\
\hline $\begin{array}{l}\text { Mirbagher } \\
\text { Ajorpaz vd., } 2020 \\
(43)\end{array}$ & $\begin{array}{l}\text { Her iki bacakta } \\
\text { gliserin ve } \\
\text { lavanta yağı ile } \\
\text { masaj }\end{array}$ & RKÇ & $\begin{array}{l}\text { Gliserin yağ }: 31 \\
\text { Lavanta yăg } \\
\text { grubu: } 29 \\
\text { Kontrol grubu: } 30\end{array}$ & $\begin{array}{l}\text { HD hastalarında masajının } \\
\text { HBS şiddetini azalttığı } \\
\text { görülmüştür. }\end{array}$ \\
\hline
\end{tabular}

RKÇ: Randomize kontrollü çalışma

\section{Refleksoloji}

Holistik ve tamamlayıcı bir tedavi yöntemi olan refleksoloji, özel bir basınç tekniği ile vücudun belli noktalarına, genellikle el ve ayaklara basınç uygulayarak yapılan integratif bir uygulamadır
$(2,7,50)$. Refleksoloji vücuttaki enerjiyi dengelemek, rahatlamayı ve iyileşmeyi sağlamak için eski zamandan beri kullanılmaktadır. Sağlığın korunması ve yükseltilmesinde, kronik hastalıkların semptomlarının hafifletilmesinde yaygın 
olarak kullanılmaktadır. Son yıllarda, tüm dünyada sağlık profesyonelleri arasında da oldukça popüler hale gelmiştir. $(51,52)$. Yapılan çalışmalarda refleksolojinin HD hastalarında yorgunluk, ağrı ve kramp şiddetini azalttığ 1 ve yaşam kalitesini arttırdığ 1 belirtilmektedir $(2,49,51)$. Hemodiyaliz hastalarında refleksoloji ile ilgili yapılan çalışma örnekleri Tablo 4'te gösterilmektedir.

\section{Müzik Terapi}

Terapinin uygulamaları çok eskiye dayanmaktadır. Müzik terapi, yüzyıllardır insanlık tarihinin her döneminde kullanılan ve günümüzde hala kullanılmaya devam eden bir terapi yöntemidir $(53,54)$. Müzik, bakımda önemli etkileri bulunan ve farmakolojik olmayan tamamlayıc1 bir terapidir. Son y1llarda hemşirelik uygulamalarında müzik kullanımında kayda değer bir artış görülmektedir $(55,57)$. Müzik terapi, hormonal ve fizyolojik değişiklikleri yavaş yavaş ortaya çıkarır ve dolaylı olarak duygusal durumu etkileyerek rahatlık hissi yaratır. Hemşirelik uygulamalarında, belirti ve semptomların yönetimi ve kontrolünün yanı sıra hasta-hemşire iletişimi ve ilişkisinde tamamlayıcı bir terapötik kaynak olarak tanımlanmıştır $(10,55)$. Müzik terapinin, bağımsız bir hemşirelik girişimi olarak hastaların, emosyonel, fiziksel ve psikolojik ihtiyaçları için kullanılabileceği belirtilmektedir $(57,58)$. Yapılan çalışmalarda müzik terapinin, HD hastalarında stres, kayg1 ve depresyon üzerinde yararlı etkileri olduğu, ağriyı azalttı̆̆ 1 , ruh hali ve yaşam kalitesini iyileştirdiği belirtilmiştir $(53,59,60)$. Hemodiyaliz hastalarında müzik terapi ile ilgili yapılan çalışmalar Tablo 5'te gösterilmektedir.

Tablo 4. Hemodiyaliz Hastalarında Refleksoloji Yöntemi ile İlgili Yapılan Çalışma Örnekleri

\begin{tabular}{|c|c|c|c|c|}
\hline Yazar ve yılı & $\begin{array}{c}\text { Kullanılan } \\
\text { yöntem ve } \\
\text { uygulama bölgesi }\end{array}$ & $\begin{array}{l}\text { Araştır } \\
\text { ma tipi }\end{array}$ & Örneklem & Sonuç \\
\hline $\begin{array}{l}\text { Özdemir vd., } \\
2013 \text { (7) }\end{array}$ & $\begin{array}{l}\text { Ayak } \\
\text { refleksolojisi }\end{array}$ & RKÇ & $\begin{array}{l}\text { Deney grubu: } 40 \\
\text { Kontrol grubu: } 40\end{array}$ & $\begin{array}{l}\text { Ayak refleksolojisinin HD } \\
\text { hastalarında yorgunluk düzeyini } \\
\text { azalttığı saptanmıştır }\end{array}$ \\
\hline $\begin{array}{l}\text { Unal \& Balci } \\
\text { Akpinar, } 2016 \\
(50)\end{array}$ & $\begin{array}{l}\text { Ayak } \\
\text { refleksolojisi ve } \\
\text { sirt masajı }\end{array}$ & RKÇ & $\begin{array}{l}\text { Ayak refleksoloji } \\
\text { grubu: } 35 \\
\text { Sirt masaj1 grubu: } 35 \\
\text { Kontrol grubu: } 35\end{array}$ & $\begin{array}{l}\text { Ayak refleksolojisi ve sırt } \\
\text { masajının HD hastalarının uyku } \\
\text { kalitesini arttırdığı ve } \\
\text { yorgunluğunu azalttığı } \\
\text { saptanmıştır. }\end{array}$ \\
\hline $\begin{array}{l}\text { Ghasemi vd., } \\
2018(51)\end{array}$ & $\begin{array}{l}\text { Ayak } \\
\text { refleksolojisi }\end{array}$ & RKÇ & $\begin{array}{l}\text { Deney grubu: } 35 \\
\text { Kontrol grubu: } 35\end{array}$ & $\begin{array}{l}\text { Refleksoloji uygulamasının HD } \\
\text { hastalarında HBS şiddetini } \\
\text { azalttığı saptanmıştır. }\end{array}$ \\
\hline $\begin{array}{l}\text { Ahmadidarreh } \\
\text { sima vd., } 2018 \\
(49)\end{array}$ & $\begin{array}{l}\text { Ayak } \\
\text { refleksolojisi }\end{array}$ & $\begin{array}{l}\text { Yarı } \\
\text { deneysel }\end{array}$ & $\begin{array}{l}\text { Deney grubu: } 26 \\
\text { Kontrol grubu: } 26\end{array}$ & $\begin{array}{l}\text { Ayak refleksoloji uygulamasının } \\
\text { HD hastalarında yorgunluk } \\
\text { düzeyini azalttığı saptanmıştır. }\end{array}$ \\
\hline $\begin{array}{l}\text { Naseri- } \\
\text { Salahshour } \\
\text { vd., } 2019(52)\end{array}$ & $\begin{array}{l}\text { Solar plexus ve } \\
\text { ayak tabanları }\end{array}$ & RKÇ & $\begin{array}{l}\text { Deney grubu: } 36 \\
\text { Kontrol grubu:36 }\end{array}$ & $\begin{array}{l}\text { Refleksolojinin HD hastalarında } \\
\text { bulantı şiddetini azaltmada etkili } \\
\text { olduğu saptanmıştır. }\end{array}$ \\
\hline
\end{tabular}

RKÇ: Randomize kontrollü çalışma 
Tablo 5. Hemodiyaliz Hastalarında Müzik Terapi Yöntemi ile İlgili Yapılan Çalışma Örnekleri

\begin{tabular}{|c|c|c|c|c|}
\hline Yazar ve yılı & $\begin{array}{l}\text { Kullanılan } \\
\text { müzik türü }\end{array}$ & Araştırma tipi & Örneklem & Sonuç \\
\hline $\begin{array}{l}\text { Lin vd., } 2012 \\
(10)\end{array}$ & $\begin{array}{l}\text { Hastaların } \\
\text { kendisinin } \\
\text { oluşturduğu } \\
\text { müzik listesi }\end{array}$ & RKÇ & $\begin{array}{l}\text { Deney grubu: } 44 \\
\text { Kontrol grubu: } 44\end{array}$ & $\begin{array}{l}\text { Müzik terapinin HD } \\
\text { hastalarında genel olarak } \\
\text { rahatlamayı sağladığı } \\
\text { görülmüştür. }\end{array}$ \\
\hline $\begin{array}{l}\text { Cantekin \& Tan, } \\
2013(54)\end{array}$ & $\begin{array}{l}\text { Türk sanat } \\
\text { müziği (Rast ve } \\
\text { uşak makamı) }\end{array}$ & $\begin{array}{l}\text { Ön test-son } \\
\text { test kontrol } \\
\text { gruplu } \\
\text { deneysel } \\
\text { çalışma }\end{array}$ & $\begin{array}{l}\text { Deney grubu: } 50 \\
\text { Kontrol grubu: } 50\end{array}$ & $\begin{array}{l}\text { Müzik terapinin, HD } \\
\text { hastalarının anksiyete ve } \\
\text { algılanan stres düzeyini } \\
\text { azaltmada etkili olduğu } \\
\text { görülmüştür. }\end{array}$ \\
\hline $\begin{array}{l}\text { Burrai vd., } 2014 \\
(53)\end{array}$ & $\begin{array}{l}\text { Saksafon } \\
\text { müziği }\end{array}$ & RKÇ & $\begin{array}{l}\text { Deney grubu: } 57 \\
\text { Kontrol grubu: } 57\end{array}$ & $\begin{array}{l}\text { Müzik terapinin, HD } \\
\text { hastalarının ağrı, ruh hali, } \\
\text { kaşıntı seviyesi ve oksijen } \\
\text { satürasyon düzeyi üzerinde } \\
\text { olumlu etkilerinin olduğu } \\
\text { saptanmıştır. }\end{array}$ \\
\hline $\begin{array}{l}\text { Koca Kutlu \& } \\
\text { Eren, } 2014 \text { (57) }\end{array}$ & $\begin{array}{l}\text { Türk sanat } \\
\text { müziği }\end{array}$ & RKÇ & $\begin{array}{l}\text { Deney grubu: } 30 \\
\text { Kontrol grubu: } 30\end{array}$ & $\begin{array}{l}\text { Müzik terapinin, HD } \\
\text { hastalarının ağrı seviyesini } \\
\text { azalttığı saptanmıştır. }\end{array}$ \\
\hline $\begin{array}{l}\text { Karadağ \& } \\
\text { Karadakovan, } \\
2015(55)\end{array}$ & $\begin{array}{l}\text { Türk sanat } \\
\text { müziği }\end{array}$ & RKÇ & $\begin{array}{l}\text { Deney grubu: } 35 \\
\text { Kontrol grubu: } 35\end{array}$ & $\begin{array}{l}\text { Müzik terapinin, HD } \\
\text { hastalarının yaşamsal } \\
\text { parametreler ve uyku } \\
\text { kalitesi üzerinde olumlu } \\
\text { etkilerinin olduğu } \\
\text { saptanmıştır. }\end{array}$ \\
\hline $\begin{array}{l}\text { Kim vd., } 2015 \\
(58)\end{array}$ & Müzik terapi & $\begin{array}{l}\text { Meta-analiz } \\
\text { çalışması }\end{array}$ & 7 çalışma & $\begin{array}{l}\text { Müzik terapinin, HD } \\
\text { sırasında hastalarda } \\
\text { rahatlama, gevşeme } \\
\text { sağladığı ve kaygıyı } \\
\text { azalttığı saptanmıştır. }\end{array}$ \\
\hline $\begin{array}{l}\text { Shabandokht- } \\
\text { Zarmi vd., } 2017 \\
\text { (59) }\end{array}$ & $\begin{array}{l}\text { Geleneksel } \\
\text { /sakinleştirici } \\
\text { müzik }\end{array}$ & RKÇ & $\begin{array}{l}\text { Müzik grubu: } 38 \\
\text { Kulaklık grubu: } 38 \\
\text { Kontrol grubu: } 38\end{array}$ & $\begin{array}{l}\text { HD hastalarında fistül iğne } \\
\text { girişine bağlı ağrılarda } \\
\text { müzik terapinin etkin bir } \\
\text { şekilde kullanılabileceği } \\
\text { sonucuna varılmıştır. }\end{array}$ \\
\hline $\begin{array}{l}\text { Melo vd., } 2018 \\
(56)\end{array}$ & $\begin{array}{l}\text { Vivaldi, Dört } \\
\text { Mevsim'den } \\
\text { Klasik Bahar } \\
\text { Şarkısı }\end{array}$ & RKÇ & $\begin{array}{l}\text { Deney grubu: } 30 \\
\text { Kontrol grubu: } 30\end{array}$ & $\begin{array}{l}\text { Müzik terapinin, HD } \\
\text { hastalarında anksiyete ve } \\
\text { yaşamsal parametreler } \\
\text { üzerinde terapötik etkisinin } \\
\text { olduğu saptanmıştır. }\end{array}$ \\
\hline $\begin{array}{l}\text { Kishida vd., } 2019 \\
(60)\end{array}$ & Mozart & RKÇ & 120 Hasta & $\begin{array}{l}\text { Müzik terapinin, HD } \\
\text { hastalarında kanül girişi } \\
\text { sırasında oluşan ağrıyı } \\
\text { azalttığı saptanmıştır. }\end{array}$ \\
\hline
\end{tabular}

RKÇ: Randomize kontrollü çalışma

\section{SONUÇ}

Dünyada ve ülkemizde integratif yöntemlere olan ilginin artmas1, hastalarda integratif yöntemlerin kullanımının yaygınlaşmasına neden olmuştur.
HD hastalarında ağrı, yorgunluk, kramplar, anksiyete, kaygı, depresyon, kaşıntı, uyku bozuklukları gibi birçok semptomun yönetiminde integratif yöntemler kullanılmaktadır. Yapılan çalışma- 
larda aromaterapi, akupunktur, akupresür, masaj, refleksoloji müzik terapi gibi integratif yöntemlerin bu semptomlar üzerinde etkili olduğu görülmektedir. Bu nedenle hemşireler, hastaların HD’ye bağlı sıklıkla yaşadığı semptomları ile başa çıkmalarında onlara danışmanlık yaparak kullanabilecekleri kanıta dayalı integratif yöntemler hakkında hastaları bilgilendirmelidir. Hemşireler tüm bunları yaparken gerekli bilgi donanımına sahip olmalı ayrıca bilgisini uygulamaya aktarma konusunda da istekli ve yetenekli olmalidir.

\section{Teşekkür/Acknowledgements}

\section{Finansal destek/ Financial support}

Yazarlar herhangi bir finansal destek beyan etmemişlerdir.

\section{Çıkar çatışması// Conflict of interests}

Yazarlar herhangi bir çıkar çatışması olmadığını beyan etmişlerdir.

\section{Hakemlik/ Reviewing}

Çift kör hakemlik süreçleri uygulanmıştır.

\section{Yazarlık Katkıları}

Çalışma fikri ve tasarımı: ZBB, MA

Makalenin hazırlanması: ZBB, MA

Eleştirel inceleme: MA, ZBB

\section{Kaynaklar}

1. Bagheri-Nesami M, Espahbodi F, Nikkhah A, Shorofi SA, Charati JY. The effects of lavender aromatherapy on pain following needle insertion into a fistula in hemodialysis patients. Complementary Therapies in Clinical Practice 2014;20(1):1-4.

2. Luyckx VA, Tonelli M, Stanifer JW. The global burden of kidney disease and the sustainable development goals. Bulletin of the World Health Organization 2018;96(6):414-422D.

3. Süleymanlar G, Ateş K, Seyahi N. T.C. Sağlık Bakanlığı ve Türk Nefroloji Derneği Ortak Raporu. 2020;136. http://www.nefroloji.org.tr/folders/file/registry_2019.pdf Erişim Tarihi: 30.01.2021

4. Ovayolu N, Ovayolu Ö, Güngörmüş Z, Karadağ G. Böbrek Yetmezliğinde Tamamlayıcı Tedaviler. Nefroloji Hemşireliği Dergisi 01 Mart 2015;10(1):40-6.

5. Bouya S, Ahmadidarehsima S, Badakhsh M, Balouchi A, Koochakzai M. Effect of aromatherapy interventions on hemodialysis complications: A systematic review. Complementary Therapies in Clinical Practice 01 2018;32:130-8.

6. Sabouhi F, Kalani L, Valiani M, Mortazavi M, Bemanian M. Effect of acupressure on fatigue in patients on hemodialysis. Iranian Journal of Nursing and Midwifery Research 2013;18(6):429-34.

7. Özdemir G, Ovayolu N, Ovayolu O. The effect of reflexology applied on haemodialysis patients with fatigue, pain and cramps. International Journal of Nursing Practice 2013;19(3):265-73.

8. Şentürk A, Tekinsoy Kartın P. The Effect of Lavender Oil Application via Inhalation Pathway on Hemodialysis Patients' Anxiety Level and Sleep Quality. Holist Nurs Pract. 2018;32(6):324-35.

9. Mohmadi K, Shahgholian N, Valiani M, Mardanparvar H. The effect of acupressure on muscle cramps in patients undergoing hemodialysis. Iranian Journal of Nursing and Midwifery Research 2016;21(6):557-61

10. Lin Y-J, Lu K-C, Chen C-M, Chang C-C. The effects of music as therapy on the overall well-being of elderly patients on maintenance hemodialysis. Biological Research For Nursing 2012;14(3):277-85.

11. Aliasgharpour M, Abbaszadeh R, Mohammadi N, Kazemnejad A. Effect of lavender aromatherapy on the pain of arteriovenous fistula puncture in patients on hemodialysis. Nursing Practice Today. 2016;3(1):26-30.

12. Reyes MCGM, Reyes MCGM, Ribay KGL, Paragas ED. Effects of sweet orange aromatherapy on pain and anxiety during needle insertion among patients undergoing hemodialysis: A quasi-experimental study. Nursing Forum (Auckl). 2020;55(3):425-32.

13. Lee E-J, Kim B-S, Sa I-H, Moon K-E, Kim J-H. The Effects of Aromatherapy on Sleep Disorders, Satisfaction of Sleep and Fatigue in Hemodialysis Patients. Korean Journal of Adult Nursing. 2011;23(6):615-23.

14. Dabirian A, Sadeghim M, Mojab F, Talebi A. The Effect of Lavender Aromatherapy on Sleep Quality in Hemodialysis Patients. Advances in Nursing \& Midwifery 2013;22(79):8-16.

15. Cürcani M, Tan M. The effect of aromatherapy on haemodialysis patients' pruritus. Journal of Clinical Nursing 2014;23(23-24):3356-65.

16. Bagheri-Nesami M, Shorofi SA, Nikkhah A, Espahbodi F, Koolaee FSG. The effects of aromatherapy with lavender essential oil on fatigue levels in haemodialysis patients: A randomized clinical trial. Complementary Therapies in Clinical Practice 10 2015;22:33-7. 
17. Ghods AA, Abforosh NH, Ghorbani R, Asgari MR. The effect of topical application of lavender essential oil on the intensity of pain caused by the insertion of dialysis needles in hemodialysis patients: A randomized clinical trial. Complementary Ttherapies in Medicine 2015;23(3):325-30.

18. Hashemi SH, Hajbagheri A, Aghajani M. The Effect of Massage With Lavender Oil on Restless Leg Syndrome in Hemodialysis Patients: A Randomized Controlled Trial. Nursing and Midwifery Studies 2015;4(4):e29617.

19. Barati F, Nasiri A, Akbari N, Sharifzadeh G. The Effect of Aromatherapy on Anxiety in Patients. Nephro- NephroUrology Monthly 2016;8(5):e38347.

20. Bagheri-Nesami M, Shorofi SA, Nikkhah A, Espahbodi F. The effects of lavender essential oil aromatherapy on anxiety and depression in haemodialysis patients. Pharmaceutical and Biomedical Research 2017;3(1):8-13.

21. Muz G, Taşcı S. Effect of aromatherapy via inhalation on the sleep quality and fatigue level in people undergoing hemodialysis. Applied Nursing Research:ANR. 2017;37:28-35.

22. Hassanzadeh M, Kiani F, Bouya S, Zarei M. Comparing the effects of relaxation technique and inhalation aromatherapy on fatigue in patients undergoing hemodialysis. Complement Ther Clin Pract. 2018;31:210-4.

23. Ahmady S, Rezaei M, Khatony A. Comparing effects of aromatherapy with lavender essential oil and orange essential oil on fatigue of hemodialysis patients: A randomized trial. Complementary Therapies in Clinical Practice 2019;36:64-8.

24. Karadag E, Samancioglu Baglama S. The Effect of Aromatherapy on Fatigue and Anxiety in Patients Undergoing Hemodialysis Treatment: A Randomized Controlled Study. Holistic Nursing Practice 2019;33(4):222-9.

25. Taşan E, Ovayolu O, Ovayolu N. The effect of diluted lavender oil inhalation on pain development during vascular access among patients undergoing haemodialysis. Complementary Therapies in Clinical Practice 2019;35:177-82.

26. Efe Arslan D, Kılıç Akça N. The effect of aromatherapy hand massage on distress and sleep quality in hemodialysis patients: A randomized controlled trial. Complementary Therapies in Clinical Practice 2020;39:101136.

27. Mohammadpourhodki R, Sadeghnezhad H, Ebrahimi H, Basirinezhad MH, Maleki M, et al. The Effect of Aromatherapy Massage With Lavender and Citrus Aurantium Essential Oil on Quality of Life of Patients on Chronic Hemodialysis: A Parallel Randomized Clinical Trial Study. Journal of Pain and Symptom Management 2020. doi: 10.1016/j.jpainsymman.2020.08.032

28. Varaei S, Jalalian Z, Yekani Nejad MS, Shamsizadeh M. Comparison the effects of inhalation and massage aromatherapy with lavender and sweet orange on fatigue in hemodialysis patients: a randomized clinical trial. Journal of Complementary and Integrative Medicine 2020; Online ahead of print. doi: 10.1515/jcim-2018-0137

29. Hadadian F, Sohrabi N, Farokhpayam M, Farokhpayam H, Towhidi F, et al. The Effects of Transcutaneous Electrical Acupoint Stimulation (TEAS) on Fatigue in Haemodialysis Patients. Journal of Clinical and Diagnostic Research:JCDR. 2016;10(9):YC01-4.

30. Zou C, Yang L, Wu Y, Su G, Chen S, et al. Auricular acupressure on specific points for hemodialysis patients with insomnia: a pilot randomized controlled trial. PloS One. 2015;10(4):e0122724.

31. Wu Y, Zou C, Liu X, Wu X, Lin Q. Auricular acupressure helps improve sleep quality for severe insomnia in maintenance hemodialysis patients: a pilot study. J Altern Complement Med N Y N. 2014;20(5):356-63.

32. Yu J-S, Ho C-H, Wang H-Y, Chen Y-H, Hsieh C-L. Acupuncture on Renal Function in Patients with Chronic Kidney Disease: A Single-Blinded, Randomized, Preliminary Controlled Study. Alternative and Complementary Medicine 2017;23(8):624-31.

33. Eğlence R, Karataş N, Taşci S. The effect of acupressure on the level of fatigue in hemodialysis patients. Alternative Therapies in Health and Medicine 2013;19(6):23-31.

34. Shariati A, Jahani S, Hooshmand M, Khalili N. The effect of acupressure on sleep quality in hemodialysis patients. Complementary Therapies in Medicine 2012;20(6):417-23.

35. Kılıç Akça N, Taşçi S, Karataş N. Effect of acupressure on patients in Turkey receiving hemodialysis treatment for uremic pruritus. Alternative Therapies in Health and Medicine 2013;19(5):12-8.

36. Hmwe NTT, Subramanian P, Tan LP, Chong WK. The effects of acupressure on depression, anxiety and stress in patients with hemodialysis: a randomized controlled trial. International Journal of Nursing Studies 2015;52(2):509-18.

37. Arab Z, Shariati AR, Asayesh H, Vakili MA, Bahrami-Taghanaki H, Azizi H. A Sham-Controlled Trial of Acupressure on the Quality of Sleep and Life in Haemodialysis Patients. Acupuncture in Medicine 2016;34(1):2-6.

38. Shen K, Cho Y, Pascoe EM, Hawley CM, Oliver V, et al. The SIESTA Trial: A Randomized Study Investigating the Efficacy, Safety, and Tolerability of Acupressure versus Sham Therapy for Improving Sleep Quality in Patients with End-Stage Kidney Disease on Hemodialysis, Evidence-Based Complementary and Alternative Medicine. Hindawi; 2017 s. e7570352. doi: 10.1155/2017/7570352

39. Nahidi Y, Badiee S, Torabi S, Shaye ZA, Nazemian F, et al. Acupuncture effect on pruritus in hemodialysis patients: A randomized clinical trial. Iranian Red Crescent Medical Journal 2018;20(10).

40. Abbasi P, Mojalli M, Kianmehr M, Zamani S. Effect of acupressure on constipation in patients undergoing hemodialysis: A randomized double-blind controlled clinical trial. Avicenna Journal of Phytomedicine 2019;9(1):84-91. 
41. Karjalian F, Momennasab M, Yoosefinejad AK, Jahromi SE. The Effect of Acupressure on the Severity of Pruritus and Laboratory Parameters in Patients Undergoing Hemodialysis: A Randomized Clinical Trial. J Journal of Acupuncture and Meridian Studies 2020;13(4):117-23.

42. Wang X, Gu J, Liu J, Hong H. Clinical evidence for acupressure with the improvement of sleep disorders in hemodialysis patients: A systematic review and meta-analysis. Complementary Therapies in Clinical Practice 2020;39:101151.

43. Mirbagher Ajorpaz N, Rahemi Z, Aghajani M, Hashemi SH. Effects of glycerin oil and lavender oil massages on hemodialysis patients' restless legs syndrome. Journal of Bodywork and Movement Therapies 2020;24(1):88-92.

44. Shahdadi H, Hodki RM, Aliabadi A, Sheikh A, Moghadasi A. The effect of slow stroke back massage on fatigue in patients undergoing hemodialysis: A randomized clinical trial. International Journal of Pharmacy \& Technology 2016;8:16016-23.

45. Aghajani M, Kheirkhah D. The effect of massage with glycerin oil on restless leg syndrome in hemodyalysis patients. Complementary Medicine Journal 2016;6(2):1500-10.

46. Ghavami H, Shamsi SA, Abdollahpoor B, Radfar M, Khalkhali HR. Impact of hot stone massage therapy on sleep quality in patients on maintenance hemodialysis: A randomized controlled trial. Journal of Research in Medical Sciences : The Official Journal of Isfahan University of Medical Sciences 2019;24:71.

47. Khorsand A, Salari R, Noras MR, Saki A, Jamali J, et al. The effect of massage and topical violet oil on the severity of pruritus and dry skin in hemodialysis patients: A randomized controlled trial. Complementary Therapies in Medicine 2019;45:248-53.

48. Habibzadeh H, Wosoi Dalavan O, Alilu L, Wardle J, Khalkhali H, et al. Effects of Foot Massage on Severity of Fatigue and Quality of Life in Hemodialysis Patients: A Randomized Controlled Trial. International Journal of Community Based Nursing and Midwifery 2020;8(2):92-102.

49. Ahmadidarrehsima S, Mohammadpourhodki R, Ebrahimi H, Keramati M, Dianatinasab M. Effect of foot reflexology and slow stroke back massage on the severity of fatigue in patients undergoing hemodialysis: A semi-experimental study. Journal of Complementary \& Integrative Medicine 2018;15(4). doi: 10.1515/jcim-2017-0183

50. Unal KS, Balci Akpinar R. The effect of foot reflexology and back massage on hemodialysis patients' fatigue and sleep quality. Complementary Therapies in Clinical Practice 2016;24:139-44.

51. Ghasemi M, Rejeh N, Heravi-Karimooi M, Tadrisi SD, Samady Kia P. The Effectiveness of Foot Reflexology in the Severity of Restless Legs Syndrome in Female Patients Undergoing Dialysis: A Randomized Controlled Trial. Critical Care Nursing 2018;11(2).

52. Naseri-Salahshour V, Sajadi M, Abedi A, Fournier A, Saeidi N. Reflexology as an adjunctive nursing intervention for management of nausea in hemodialysis patients: A randomized clinical trial. Complementary Therapies in Clinical Practice 2019;36:29-33.

53. Burrai F, Micheluzzi V, Zito MP, Pietro G, Sisti D. Effects of live saxophone music on physiological parameters, pain, mood and itching levels in patients undergoing haemodialysis. Journal of Renal Care 2014;40(4):249-56.

54. Cantekin I, Tan M. The influence of music therapy on perceived stressors and anxiety levels of hemodialysis patients. Renal Failure 2013;35(1):105-9.

55. Karadağ E, Karadakovan A. The Effect of Music on the Sleep Quality and Vital Signs of the Chronic Renal Failure Patients Who are Getting Hemodialysis Treatment. Turkiye Klinikleri Journal of Nursing Sciences 2015;7(2):79-89.

56. Melo GAA, Rodrigues AB, Firmeza MA, Grangeiro AS de M, Oliveira PP de, et al. Musical intervention on anxiety and vital parameters of chronic renal patients: a randomized clinical trial. Revista Latino-Americana de Enfermagem 2018;26:e2978.

57. Koca Kutlu A, Eren AG. Effects of music on complications during hemodialysis for chronic renal failure patients. Hemodialysis international 2014;18(4):777-84.

58. Kim Y, Evangelista LS, Park Y-G. Anxiolytic Effects of Music Interventions in Patients Receiving Incenter Hemodialysis: A Systematic Review and Meta-Analysis. Nephrology Nursing Journal: Journal of the American Nephrology Nurses' Association 2015;42(4):339-47; 348.

59. Shabandokht-Zarmi H, Bagheri-Nesami M, Shorofi SA, Mousavinasab SN. The effect of self-selected soothing music on fistula puncture-related pain in hemodialysis patients. Complementary Therapies in Clinical Practice 2017;29:53-7.

60. Kishida M, Yamada Y, Inayama E, Kitamura M, Nishino T, et al. Effectiveness of music therapy for alleviating pain during haemodialysis access cannulation for patients undergoing haemodialysis: a multi-facility, single-blind, randomised controlled trial. Trials 2019;20(1):631. 